\title{
Influence of Setting Condition on Characteristics of Savonius Hydraulic Turbine with a Shield Plate
}

\author{
Shouichiro Iio ${ }^{1}$, Yusuke Katayama ${ }^{2}$, Fuminori Uchiyama ${ }^{3}$, Eiichi Sato ${ }^{4}$ and Toshihiko Ikeda ${ }^{1}$ \\ 1. Faculity of Eng., Shinshu University, 4-17-1 Wakasato, Nagano, JAPAN, 380-8553 \\ 2. Student of Shinshu University, 4-17-1 Wakasato, Nagano, JAPAN, 380-8553 \\ 3. Flowserve Niigata Worthington Co., Ltd., 1-32 Shinbashi, Kashiwazaki, Niigata, JAPAN, 945-0056 \\ 4. Faculty of Eng., Niigata Institute of Technology,1719 Fujihashi, Kashiwazaki, Niigata, JAPAN, 945-1195 \\ (C) Science Press and Institute of Engineering Thermophysics, CAS and Springer-Verlag Berlin Heidelberg 2010
}

\begin{abstract}
The aim of this investigation was to improve power performance of Savonius hydraulic turbine utilizing small stream for electric generation. An attempt was made to increase the power coefficient of runner by the use of flat shield plate placed upstream of the runner. The difference of the power coefficient is discussed in relation to clearance between the runner and the bottom wall and the rotation direction of the runner. The flow field around the runner was also examined visually to clarify influences of setting conditions on the power performance. From this study it was found that the power coefficient is achieved for 0.47 by only using a flat shield plate, the increase is up to $80 \%$ over the runner without the plate. Moreover, it is the proper condition that clearance ratio is 0.73 in this study.
\end{abstract}

\section{Keywords: Nano-hydraulic turbine, Savonius runner, Shield plate, Performance}

\section{Introduction}

Environmental issues as typified by global warming become conspicuous in recent years. It is obvious that using natural energy effectively leads achieving sustainable energy. The hydropower should occupy the attention of electric power generating systems as it is clean and renewable energy source with highest density, in cooperation with the wind and the solar powers. Most of hydropower is generated by the large-scale hydroelectric plant. Some have suggested that dam constructions can lead to the tremendous environmental damages. On the other hand, small/micro/nano hydropower has attracted much attention in recent years mainly because of decrease of construction place for large-scale plants and environmental conservation. The aim of this study is to develop a Savonius type hydraulic turbine to utilize small stream effectively as the nano-hydropower and a dispersed power system. The turbine is suitable for the rivers or the irrigation canals in which the effective head is not sufficient while the flow rate is enough. It is thought that this approach could lead to cheaper power generation without the environmental destruction, compared with that produced by large-scale hydroelectric plants.

Savonius runner has been used mainly for a wind power $^{(1)-(20)}$ and tidal/wave power generation ${ }^{(21)-(23)}$. There have been many studies of Savonius runner, e.g. runner configuration $^{(1)-(3)}$, the flow field around a runner ${ }^{(4)-(6)}$, numerical simulations ${ }^{(7),(8)}$, effect of guide vanes set around a runner ${ }^{(5),(9)-(14)}$ and others. Attempts have been made for the performance improvement of low-efficiency Savonius runners by optimizing both runner shape and 
wind collector.

The performance improvement of the Savonius runner is an important challenge also in this article for practical using of the hydraulic turbines. Until now, Nakajima et al. first attempted to improve the efficiency by applying a phase difference to the blades of the Savonius rotor ${ }^{(24)}$. This runner had 90-degrees phase difference in the blades between both sides of the partition plate. Additionally, they revealed that the power performance changes depend on the distance between the runner and the bottom wall of channel, and the rotation direction of the runner ${ }^{(25)}$. The maximum power coefficient was reached at $C_{P \max }=0.26$ under the best installation condition for small rivers. This method is more conventional than installing guide vanes or others around the runner, and is expected to improve the performance without losing the advantage of the Savonius runner, i.e. the easy maintenance, durability and low cost. But it is still necessary to greatly improve the power coefficient from the practical stand point of view. Therefore Iio et al. investigated the performance improvement by installing a flat plate (shield plate) upstream the runner considering installation cost. As a result, the power coefficient was reached at $C_{P \max }=0.47^{(26)}$. It was because the shield plate blocked the stagnation flow toward the convex side of returning blade, and accelerated the flow velocity toward concave side of advancing blade.

The goal of this investigation is to achieve higher runner performance. But it was still not clarified the optimum installation condition attaching the shield plate when practically setting the turbine in the rivers.

The purpose of this experimental study is to clarify the effect of the water surface and bottom wall on the power performance with shield plate.

\section{Experimental Apparatus and Procedure}

A schematic of the test model orientation, instrumentation, load and measurement system is shown in Fig. 1. The runner consists of rotating components held by bearings in the side plates and in the upper support structure. One end of the runner shaft is coupled to a pulley and to upper mounted load and torque meter by a timing belt on pulley. The details around the test section is also shown in Fig. 1. The runner is placed at $1500 \mathrm{~mm}$ downstream from the nozzle exit of the water circuit tunnel. Origin of coordinate system is under the center of runner shaft, the $x$-axis is along the flow direction, the $y$-axis is in the horizontal direction perpendicular to the flow, and the $z$-axis is in the depth-wise direction. The mean velocity at the center of the test section was set as $U_{0}=0.8 \mathrm{~m} / \mathrm{s}$ in the case without the runner. When the runner is placed in the test section, the flow velocity decreases and the water level becomes slightly higher than that before the runner installation. But through this experiment, the pump speed of the circuit tunnel was kept constant. The flow velocity distribution in the test section is uniform except for near the side and bottom walls in the tunnel. The normal water level in the test section is set as $H_{0}=0.4 \mathrm{~m}$. The distance between the runner and the bottom wall of the tunnel is varied 0.033 to $0.154 \mathrm{~m}$, and is defined as $H_{C}$; accordingly the clearance ratio $H_{C} / D_{R}$ is changed from 0.23 to 1.08 . A shield plate is using a flat plate because of study of Ogawa et al. that estimated the shape of the shield plate ${ }^{(12)}$, and also from point of cost and maintenance.

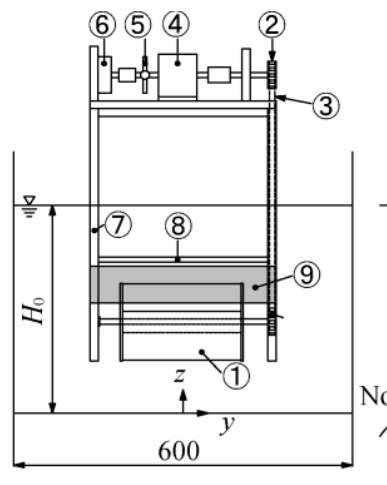

(1) Savonius runner

(4) Torque meter

(7) Side plate
(2) Pulley

(5) Rotation meter

(8) Upper plate

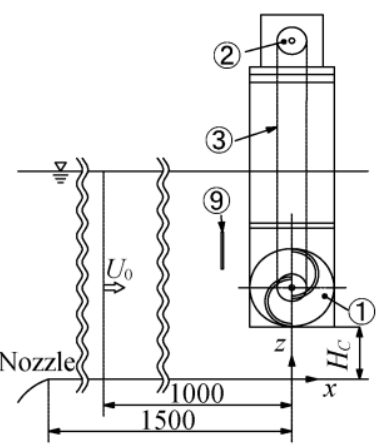

(3) Belt

(6) Load

(9) Shield plate
Fig. 1 Test section

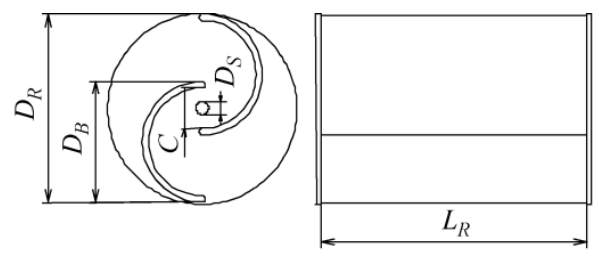

Fig. 2 Savonius runner

For the shield plate, the height is $D_{R} / 2$, the width is 1.5 times $L_{R}$, and the setting and the tilting positions are fixed at $\alpha=-30^{\circ}, \beta=90^{\circ}$. These angles are defined that $0^{\circ}$ is parallel to the flow, then the angle takes positive on clockwise. The runner rotation direction is also defined as CW (clockwise) or CCW (counterclockwise) when the main flow direction is from left to right. A rotation angle of the runner is defined as $\theta$ which corresponds to the main flow direction is $\theta=0^{\circ}$. Savonius runner was used in this experiment as shown in Fig. 2. Savonius runner (single-step runner) consists of two half-cylinder shaped blades and two endplates. The runner was constructed from stainless steel mounted on a $10.0 \mathrm{~mm}$ diameter shaft. Runner diameter is $D_{R}=0.142 \mathrm{~m}$ and length is $L_{R}=0.21 \mathrm{~m}$. Power coefficient $C_{P}$ and tip speed ratio $\lambda$ are defined as 
follows:

$$
\begin{gathered}
C_{P}=2 P / \rho A U_{0}{ }^{3} \\
\lambda=V_{t} / U_{0}
\end{gathered}
$$

Where $P$ is power output from runner, $\rho$ is water density, $A$ is projected area of runner, $V_{t}$ is runner tip speed, $\omega$ is angular velocity of runner, $T$ is torque experienced by runner. Positive direction of $\alpha, \beta$ and $\theta$ is the same as runner rotation direction. A blade which located in the range $0^{\circ} \leqslant \theta \leqslant 180^{\circ}$ is named advancing blade, that located in the range $180^{\circ} \leqslant \theta \leqslant 360^{\circ}$ is named returning blade.

\section{Results and Discussion}

At first, the influence of $H c$ on power performance was evaluated. Figure 3 shows power coefficient curves in the case of with and without the shield plate. The plate setting angles were fixed at $\alpha=-30^{\circ}, \beta=90^{\circ}$. Figure (a) is the result for $\mathrm{CW}$ rotation, and Fig. (b) is that for $\mathrm{CCW}$ rotation. All performance curves without the shield plate have the maximum power coefficient $\left(C_{P \max }\right)$ at approximately $\lambda=1.1$. It does not depend on the rotation direction. As increase of $H c, C_{P}$ and $C_{P \max }$ increases for $\mathrm{CW}$ rotation, on the contrary, decreases for $\mathrm{CCW}$ rotation. It is the most important fact that the performance is enhanced remarkably by using a shield plate. For $\mathrm{CW}$ rotation, the maximum power coefficient of $H_{C} / D_{R}=0.73$ is the maximum in all clearance ratios. For $\mathrm{CCW}$ rotation, the $C_{P \max }$ is obtained for $H_{C} / D_{R}=0.23$. The value of $\lambda$ under unloaded condition is larger than that without the shield plate. This tendency strengthens as close to the water surface for $\mathrm{CW}$ rotation, as close to the bottom wall for $\mathrm{CCW}$ rotation.

Figure 4 illustrates the variation of $C_{P \max }$ with $H_{C} / D_{R}$. It is obviously recognized that the $C_{P \max }$ is enhanced in $H_{C} / D_{R}>0.73$ for $\mathrm{CW}$ and in $H_{C} / D_{R}<0.73$ for CCW. Similar pattern can also be seen in the case without the shield plate. For $H_{C} / D_{R}=0.73$, the power coefficient has the maximum value of $C_{P \max }=0.47$ for $\mathrm{CW}$ with the shield plate, it is improved up to $80 \%$. From the result of performance for $\mathrm{CW}$ with the shield plate, the water surface has little effect on the runner performance. The power coefficient of $H_{C} / D_{R}=1.08$ for CCW decreases by $15 \%$ than $C_{P \max }$ of $H_{C} / D_{R}=0.73$. $C_{P \max }$ for $\mathrm{CW}$ with the shield plate rapidly decreases with $H_{C} / D_{R}$. Both $C_{P}$ and $C_{P \max }$ are the same as $H_{C} D_{R}=0.73$ for $\mathrm{CCW}$ with the shield plate under the installation condition near the bottom wall. For $\mathrm{CCW}$, the flow near the bottom wall has little effect to the runner performance. It can be said that $C_{P \max }$ with the shield plate is weakened near the water surface of $\mathrm{CW}$ and near the bottom wall of CCW. Ueno et al. ${ }^{(11)}$ studied the influence of flat plate for wind collector on performance of Savonius wind runner. They reported that the performance of the Savonius runner improved with increasing the distance between the blade and the flat plate. Nakajima et al. applied the study for hydraulic turbine ${ }^{(25)}$. The flat plate was the equivalent of the bottom wall of the water tunnel. The similar reason is for the power performance changed with the distance between the runner and the bottom wall. In this study, the similar result is also obtained on the power performance. To investigate the cause of the change in the power performance by the distance between runner and bottom wall, we focused on the flow field in and around the runner using the pigment streak-line method. The injection point was set at $x=-200 \mathrm{~mm}$ on the central section of runner width. The visualization results are shown in Fig. 5 (a) to (d). When we compare the results for CW rotation shown in Fig. (a) and (b), separation vortices from top and bottom tip of the shield plate were observed as shown in Fig. (a), it seems that the wake region is wider than that for $H_{C} / D_{R}=0.23$ in Fig. (b). Figure (b) shows only separation vortex from upper tip of the shield plate. Therefore, the negative pressure region formed downstream the shield plate has effect on dragging the returning blade. As a consequence, rotation of runner was en-

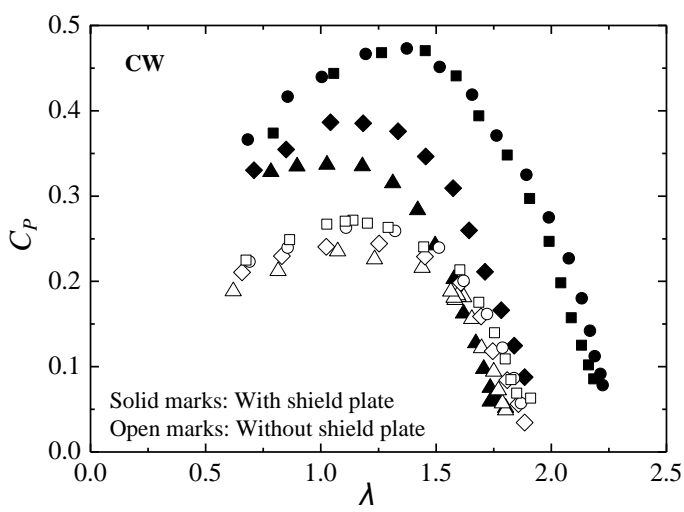

(a) $\mathrm{CW}$ rotation

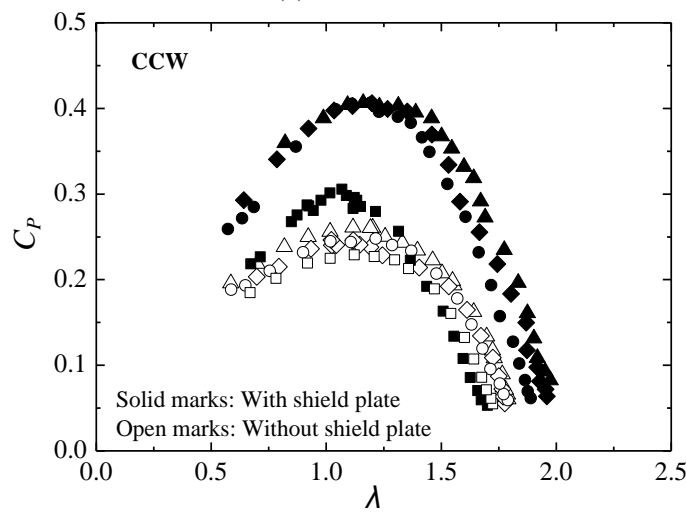

(b) $\mathrm{CCW}$ rotation

$$
\begin{aligned}
& H_{C} / D_{R}=\boldsymbol{\Delta} 0.23 \diamond 0.38 \quad \bullet \quad 0.73 \quad \square \quad 1.08 \\
& \triangle 0.23 \diamond 0.38 \quad \bigcirc 0.73 \quad \square 1.08
\end{aligned}
$$

Fig. 3 Power performance $\left(\alpha=-30^{\circ}, \beta=90^{\circ}\right)$ 
hanced because of blocking effect of stagnation flow toward a returning blade and of occurring negative pressure upstream the returning blade. For $\mathrm{CCW}$ rotation as shown in Fig. 5(c) and (d), it can be easily recognized that the flow over the shield plate and through between the shield plate and the upper plate is apparently different. For $H_{C} / D_{R}=0.73$, the flow toward the returning blade is not observed. As a result, it is clear that the size of wake region and the block effect of stagnation flow toward the returning blade are most important factors to improve the power coefficient of Savonius runner with shield plate. And the water surface and the bottom wall affect on the power performance. Fig. 5(a) shows vortices from top and bottom tip of the shield plate, therefore pressure drop is remarkable. But Fig. (b) shows vortex from only top tip of the shield plate, so negative pressure behind the shield plate is lower than that of Fig. (a); accordingly it is not easy to draw the returning blade for $\mathrm{CW}$ rotation. Fig. (d) shows the impinging flow on the returning blade ow-

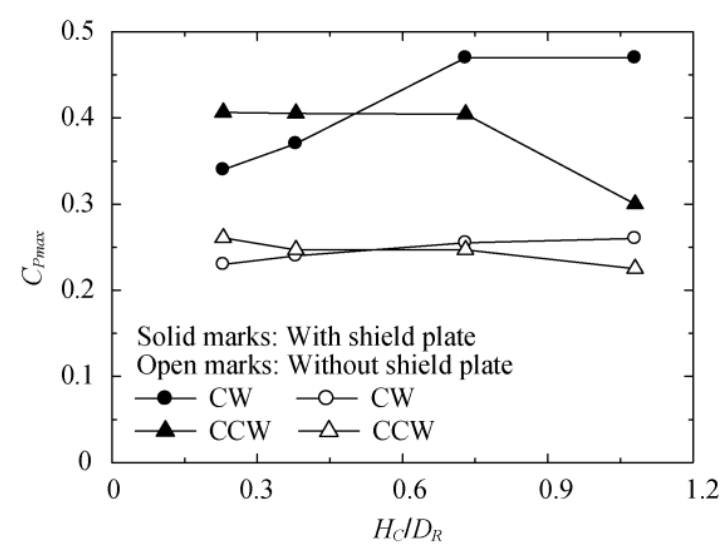

Fig. 4 Maximum power coefficient vs. clearance ratio
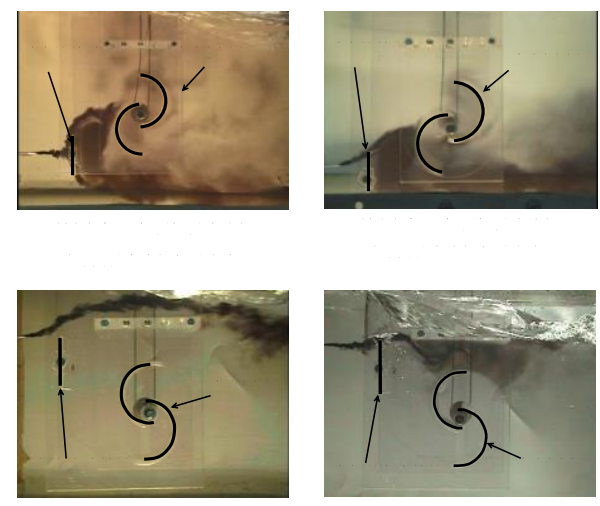

ing to the water surface for CCW.

\section{Conclusions}

The influence of the water surface and the bottom wall on the power performance is almost similar to that of runner without the shield plate. In particular, the flow near the water surface has little influence on the power performance for $\mathrm{CW}$ rotation, on the other hand, influence of the bottom wall is small for CCW rotation.

The power coefficient is reached at 0.47 by only using a flat shield plate, the increase of approximately $80 \%$ over the runner without the plate. The rotation speed of the runner is almost enhanced by the shield plate. The best orientation conditions of the runner with the shield plate are as follows; the clearance ratio defined the distance between the runner and the bottom wall of channel to the runner diameter is 0.73 .

\section{Acknowledgement}

This work was partly supported by KAKENHI No.2231004 and Ministry of Environment.

\section{References}

[1] Sheldahl, R. E., Feltz, L.V. and Blackwell, B. F.: Wind Tunnel Performance Data for Two and Three-Bucket Savonius Rotors, Journal of Energy, Vol.2, No.3, pp.160-164, (1978).

[2] Sivasegaram, S.: Secondary Parameters Affecting the Performance of Resistance-type Vertical-axis Wind Rotors, Wind Engineering, Vol.2, No.1, pp.49-59, (1978).

[3] Ushiyama, I., Nagai, H. and Shinoda, J.: Experimentally Determining the Optimum Design Configuration for Savonius Rotors, Transactions of the Japan Society of Mechanical Engineers, Series B, Vol.52, No.480, pp.2973-2981 (1986), in Japanese.

[4] Bergeles, G. and Athanassiadis, N.: On the Field around a Savonius Rotors, Wind Engineering, Vol.6 No.3, pp.140-148, (1982).

[5] Murai, H., Kataoka, M., Narasaka, T., Watanabe, H. and Onuma, S.: Influence of Flaps and Deflectors on Power and Torque Characteristics of Savonius Rotor, Journal of the Visualization Society of Japan, 4-Suppl, pp.11-16, (1984) , in Japanese.

[6] Fujisawa, N., Shirai, H. and Saikawa, Y.: Investigation of the Field and Power Mechanism of a Savonius Rotor: Flow Visualization by a Smoke-wire Method, Transactions of the Japan Society of Mechanical Engineers, Series B, Vol.53, No.496, pp.3716-3721, (1987), in Japa-

Fig.5 Flow patterns 
nese.

[7] Ogawa, T.: Research of a Savonius Rotor: Part 1 Theoretical Analysis, Transactions of the Japan Society of Mechanical Engineers, Series B, Vol.49, No.441, pp.976-984, (1983), in Japanese.

[8] Ishimatsu, K., Shinohara, T. and Takuma, F.: Numerical Simulation for Savonius Rotor: Running Performance and Flow Field, Transactions of the Japan Society of Mechanical Engineering, Series B, Vol.60, No.569, pp.154-160, (1994), in Japanese.

[9] Sivasegaram, S.: Concentration Augmentation of Power in a Savonius-type Wind Rotor, Wind Engineering, Vol.3, No.1, pp.52-61, (1979).

[10] Sabzavari, A.: Performance Characteristics of Concentrator-Augmented Savonius Wind Rotors, Wind Engineering, Vol.1, No.3, pp.198-206, (1977).

[11] Ueno, H., Mino, M. and Takada, N.: Savonius type wind turbine (The influence of wind concentrator), Journal of Japan Solar Energy Society, Vol.30, No.5, pp.35-40, (2004), in Japanese.

[12] Ogawa, T., Tahara, K. and Suzuki, N.: Study on a Savonius-Type Wind Turbine: 2nd Report, Effects of Guide Vanes, Transactions of the Japan Society of Mechanical Engineers, Series B, Vol.51, No.471, pp.3516-3522, (1985), in Japanese.

[13] Sato, S., Kikuchi, K. and Ushiyama, I.: An Experimental Study on Power Augmentation of Savonius Rotor, Proceedings of JSES/JWEA Joint Conference, Memoirs of the Ashikaga Insutitute of Technology, pp.197-200, (1997).

[14] Lei, W., Kitani, O., Okamoto, T. and Torii, T.: Experimental Study on the Efficiency Increase of a Savonius Windmill (Part 1): Test of Concentrator's Performance, Journal of the Japanese Society of Agricultural Machinery, Vol.58, No.2, pp.11-17, (1996), in Japanese.

[15] Savonius, S. J., The S-Rotor and Its Applications, Mechanical Engineering, Vol.53, No.5, pp.333-338, (1931).

[16] Takaku, A. and Ogawa, Y.: Practical Application of Multi-Step Vertical-axis Wind Rotor (2nd Report, Characteristics of the Third Wind Rotor), Turbomachinery, Vol.13, No.12, pp.711-721, (1985), in Japanese.
[17] Khan, M. H.: Model and Prototype Performance Characteristics of Savonius Rotor Windmill, Wind Engineering, Vol.2, No.2, pp.75-85, (1978).

[18] Hayashi, T., Li, Yan. and Hara, Y.: Wind Tunnel Tests on a Different Phase Three-Stage Savonius Rotor $(<$ Special Issue $>$ Experimental Mechanics in Heat and Fluid Flow), JSME International Journal, Series B, Fluids and thermal engineering, Vol.48, No.1, pp.9-16, (2005).

[19] Menet, J. L.: A double-step Savonius rotor for local production of electricity: a design study, Renewable energy, Vol.29, pp.1843-1862, (2004).

[20] Suzuki, S., Kato, E. and Tachikawa, T.: Flow in the vicinity of vane of Twist Savonius Rotor, Ibaraki district conference, Hitachi, Japan, pp.137-138, (2005), in Japanese .

[21] Higo,T., Takasugi, Y., Fujiwara, T. and Noguchi, H.: Efficiency of Savonius Hydro Turbine for Tidal Current, Reports of the Government Industrial Research Institute Chugoku, No.32, pp.1-13, (1989), in Japanese.

[22] Tan, S., Shimizu, Y. and Kikuyama, K.: Experimental Studies on a Savonius Rotor with Casing, Transactions of the Japan Society of Mechanical Engineers, Series B, Vol.63, No.611, pp.2356-2363, (1997), in Japanese.

[23] Okuda, K., Watabe, T., Kondoh, H. and Yano, K.: Study of the Wave Energy Conversion System Fixed on the Seashore: Part 1 A Water Turbine of Savonius Type for Wave Power, Memoirs of the Muroran Institute of Technology, Muroran, Japan, pp.427-432, (1981), in Japanese.

[24] Nakajima, M., Iio, S. and Ikeda, T.: Performance of Double-step Savonius Rotor for Environmentally Friendly Hydraulic Turbine, Journal of Fluid Science and Technology, Vol.3, No.3, pp.410-419(2008).

[25] Nakajima, M., Iio, S. and Ikeda, T.: Performance of Savonius Rotor for Environmentally Friendly Hydraulic Turbine, Journal of Fluid Science and Technology, Vol.3, No.3, pp.420-429, (2008).

[26] Iio, S., Uchiyama, F., Sonoda, C. and Ikeda, T.: Performance Improvement of Savonius Hydraulic Turbine by using a Shield Plate, Turbomachinery, Vol.37, No.12, pp.743-748, (2009), in Japanese. 